\title{
Experiencing fear during the pandemic. The Polish version of the Fear of COVID-19 Scale.
}

\author{
Irena Pilch ${ }^{\text {Corresp., } 1}$, Zofia Kurasz ${ }^{1}$, Agnieszka Turska-Kawa ${ }^{2}$ \\ 1 Institute of Psychology, University of Silesia, Katowice, Poland \\ 2 Institute of Political Science, University of Silesia, Katowice, Poland \\ Corresponding Author: Irena Pilch \\ Email address: irena.pilch@us.edu.pl
}

Background. The Fear of COVID-19 Scale (FCV-19S) is a brief self-report measure developed at the beginning of the coronavirus pandemic (Ahorsu et al., 2020a). The scale evaluates the emotional responses to COVID-19. To date, the FCV-19S has been translated and validated in about 20 languages and has been used in many published research. The current study aimed to validate the Polish version of the FCV-19S.

Method. The FCV-19S was translated into Polish using forward- and back-translation. From May $15^{\text {th }}$ to June $15^{\text {th }} 2020$, a total of 708 community members (Sample 1: 383 persons, 209 females, Sample 2: 325 persons, 198 females) participated in the online study. The participants were recruited using online advertisements in social media. Participation was anonymous, voluntary, and without compensation. A confirmatory factor analysis was performed to test the one-factor structure of the FCV-19S. Then, measurement invariance was analyzed across samples, gender, and age groups. To assess the validity of the scale, correlations between the FCV-19S and the remaining scales were computed.

Results. Internal consistency of the FCV-19S was good in both samples (Cronbach's alpha .89 and .85). The CFA showed that the one-factor model fits the data well (RMSEA $=0.067,90 \% \mathrm{Cl}[0.059,0.094], \mathrm{CFI}=$ $0.977, \mathrm{TLI}=0.965, \mathrm{GFI}=0.986)$. The criteria for configural, metric, scalar, and strict invariance were met for all models tested. The FCV-19S scores correlated significantly with age, subjective vulnerability to the disease, neuroticism, self-reported compliance with the pandemic measures, and three kinds of preventive behavior (i.e., social distancing, hand hygiene, and disinfecting things).

Conclusion. The Polish version of the FCV-19S had a unidimensional structure, good reliability, and correlated as predicted with other variables. With the FCV-19S and the obtained results, healthcare professionals, researchers, and the government can gain more valuable information about people who may be at risk for negative psychological outcomes during the pandemic or who are not implementing protective behavior. The tool can be used in hospitals to quickly screen the level of fear in patients and minimize its severe adverse consequences. 


\section{Experiencing fear during the pandemic. The Polish version}

3 of the Fear of Covid-19 Scale

4

5

Irena Pilch ${ }^{1}$, Zofia Kurasz ${ }^{1}$, Agnieszka Turska-Kawa ${ }^{2}$

${ }^{1}$ Institute of Psychology, University of Silesia in Katowice, Poland

${ }^{2}$ Institute of Political Science, University of Silesia in Katowice, Poland

Corresponding Author:

Irena Pilch ${ }^{1}$

Bankowa 12, Katowice, 40-007, Poland

Email address: irena.pilch@us.edu.pl

\section{Abstract}

Background. The Fear of COVID-19 Scale (FCV-19S) is a brief self-report measure developed at the beginning of the coronavirus pandemic (Ahorsu et al., 2020a). The scale evaluates the emotional responses to COVID-19. To date, the FCV-19S has been translated and validated in about 20 languages and has been used in many published research. The current study aimed to validate the Polish version of the FCV-19S.

Method. The FCV-19S was translated into Polish using forward- and back-translation. From May $15^{\text {th }}$ to June $15^{\text {th }} 2020$, a total of 708 community members (Sample 1: 383 persons, 209 females, Sample 2: 325 persons, 198 females) participated in the online study. The participants were recruited using online advertisements in social media. Participation was anonymous, voluntary, and without compensation. A confirmatory factor analysis was performed to test the one-factor structure of the FCV-19S. Then, measurement invariance was analyzed across samples, gender, and age groups. To assess the validity of the scale, correlations between the FCV-19S and the remaining scales were computed.

Results. Internal consistency of the FCV-19S was good in both samples (Cronbach's alpha .89 and .85). The CFA showed that the one-factor model fits the data well (RMSEA $=0.067,90 \% \mathrm{CI}$ $[0.059,0.094], \mathrm{CFI}=0.977, \mathrm{TLI}=0.965, \mathrm{GFI}=0.986)$. The criteria for configural, metric, scalar, and strict invariance were met for all models tested. The FCV-19S scores correlated significantly with age, subjective vulnerability to the disease, neuroticism, self-reported compliance with the 
35 pandemic measures, and three kinds of preventive behavior (i.e., social distancing, hand hygiene, 36 and disinfecting things).

37 Conclusion. The Polish version of the FCV-19S had a unidimensional structure, good reliability, 38 and correlated as predicted with other variables. With the FCV-19S and the obtained results, 39 healthcare professionals, researchers, and the government can gain more valuable information 40 about people who may be at risk for negative psychological outcomes during the pandemic or 41 who are not implementing protective behavior. The tool can be used in hospitals to quickly

42 screen the level of fear in patients and minimize its severe adverse consequences. 43

\section{Introduction}

At the end of 2019, the attention of most countries in the world turned to Wuhan in 46 China, due to the increasing number of people infected by and dying from the novel coronavirus 47 (Severe Acute Respiratory Syndrome Coronavirus 2; SARS-CoV-2). The virus has spread at a 48 tremendous pace, causing a global health crisis. Infections have been confirmed in most 49 countries in the world. The World Health Organization (WHO) declared it to be a global pandemic several months later (in March 2020). The pandemic situation is a surprise and a challenge for everyone. In many countries, the pandemic takes a heavy toll and affects all aspects of people's lives, from private to work. Many occupational groups, such as healthcare professionals, were overwhelmed and exhausted from working for many hours, not to mention the fact that their work carried an enormous risk of contracting the virus. Additionally, limitation of work opportunities and a high rate of unemployment in other professional groups, financial consequences and the economic crisis had undoubtedly a negative impact on the psychophysical condition of citizens.

In Poland, the first case of Covid-19 was diagnosed on March $4^{\text {th }}$. One week later, social distancing measures were introduced. The whole country started operating in lockdown from March $14^{\text {th }}$. Poland closed its borders to non-citizens. On March $20^{\text {th }}$, "epidemic state" was introduced. Schools, universities, offices, restaurants, and stores in shopping centers were closed. Social gatherings and non-essential movements were forbidden. and methods of treating the physiological symptoms of the disease (Dong et al., 2020; Wang et al., 2020). Mental health and well-being were relegated to the background, especially in the early stages of the pandemic (Xiang et al., 2020), also due to the lack of appropriate tools to assess the growing anxiety related to COVID-19. Currently, many people require professional 
68 psychological intervention. Prolonged focus on increased infection and mortality rates, grief over 69 the loss of loved ones, and uncertainty about the future resulted in clinically significant 70 psychological symptoms in many participants, i.e., increased levels of fear (Ornell, 2020; Ahorsu 71 et al., 2020a; Lin, 2020), anxiety (Peteet, 2020), hopelessness (Shaw, 2020), irrational and 72 unclear thoughts (Ahorsu et al., 2020a), or adjustment disorders (Zhang et al., 2020). Tian et al. 73 (2020) in their study on the group of 1,060 Chinese people found that more than $70 \%$ of the 74 participants had moderate and higher levels of psychological symptoms, including obsessive75 compulsive disorder, interpersonal sensitivity, phobic anxiety, and psychoticism.

As noted by Colizzi et al. (2020), the fear of COVID-19 is one of the core factors

77 78 79 80

increasing the level of stress, exacerbating pre-existing mental health problems, and eliciting extreme anxiety reactions in time of the pandemic. This kind of fear can have many causes such as fear of getting infected, or of infecting loved ones, of being isolated from people and of contacting accidentally somebody who is infected (Lin, 2020). Thus, the proper evaluation of fear of COVID-19 is crucial. Emotions such as fear and anxiety can influence immunity, thus leading to and exacerbating disease state. What is also important, emotional responses to threats can influence individuals' behaviors during the pandemic. It has been proven that the level of fear has a significant impact on protective behavior during the pandemic. Additionally, elevated anxiety may lead to panic and misinterpretation of insignificant complaints as symptoms of the disease (Asmundson \& Taylor, 2020a; 2020b). In turn, too little anxiety of viral infection is associated with a weaker tendency to follow the rules of hygiene and maintain social distance (Taylor, 2019). Thus, there is an urgent need for conducting research to understand the complexities of human behavior during the epidemic.

In that context, it is of crucial importance to have a reliable tool available in every language to examine the levels of fear related to COVID-19 in the society. There are a number of self-report scales that measure anxiety as a state or trait. However, these scales are not suitable to assess a person's response to specific stimuli. To measure emotional responses in the pandemic situation, some new instruments have been recently developed. One of them is the Fear of COVID-19 Scale (FCV-19S; Ahorsu et al., 2020a) which has gained a lot of attention as a tool with robust psychometric properties. The main aim of the current study was to validate the Polish version of this scale. 


\section{Fear of COVID-19 Scale}

The Fear of COVID-19 Scale (FCV-19S) was originally developed for the general population in Iran to evaluate the emotional response to COVID-19 and it was published in the English version (Ahorsu et al., 2020a). Subsequently, this scale has been translated from English and validated in many languages, i.e., Arabic (Alyami et al., 2020), Bangla (Sakib et al., 2020), Brazilian Portuguese (Faro et al., 2020), English (Perz et al., 2020; Winter et al., 2020), French (Mailliez et al., 2020), Italian (Soraci et al., 2020), Malay (Pang et al., 2020), Persian (Ahorsu et al., 2020a), Spanish (Barrios et al., 2020; Huarcaya-Victoria et al., 2020; Martínez-Lorca et al., 2020), Tamil (Bharatharaj et al., 2020), Turkish (Haktanir et al., 2020; Satici et al., 2020), Urdu (Mahmood et al., 2020), Chinese (Chi et al., 2020), Hebrew (Bitan et al., 2020), Japanese (Masuyama et al., 2020), Russian-Belarusian (Reznik et al., 2020), Romanian (Stănculescu, 2021), and Taiwanese (Chang et al., 2020). Previous scale validations covered many internally varied and different in size groups, e.g., 629 adolescents from two junior high schools in Japan (Matsuyama et al., 2020), 1,700 participants aged 10-57 in China (Chi et al., 2020), or 693 members of the general Saudi population who were at least 18 years of age (Alyami et al., 2020).

The FCV-19S has been used in a number of published research on the relationships in terms of such important psychological issues as depression, anxiety and stress (Ahorsu et al., 2020a; Perz et al., 2020; Bitan et al., 2020; Alyami et al., 2020), mental wellbeing (Ahmed et al., 2020; Winter et al., 2020), specific phobia(s) (Soraci et al., 2020), satisfaction with life (Satici et al., 2020), psychological distress (Alyami et al., 2020), post-traumatic stress disorder (HuarcayaVictoria et al., 2020), generalized anxiety disorder (Tsipropoulou et al., 2020), resilience, selfcompassion (Chi et al., 2020), perceived vulnerability to disease (Masuyama et al., 2020), preventive behavior during the pandemic (Ahorsu et al, 2020b) germ aversion, or even political beliefs (Winter et al., 2020).

Considering that COVID-19 is still in a development phase, it seems to be of crucial importance to identify individuals showing an excessive level of fear with the use of a reliable tool. For this purpose, the presented study aims at developing the Polish translation and validation of that instrument to assess the fear of COVID-19. The paper also analyzes the relationships between the fear of Covid-19 and preventive behaviors during the pandemic. With the FCV-19S and the obtained results, healthcare professionals, researchers, and the government can gain more valuable information about people who may be at risk for negative psychological 
130 outcomes from the pandemic or who are not implementing protective behavior. The tool can be 131 used in hospitals to quickly screen the level of fear in patients and minimize its severe adverse consequences (Pakpour, Griffith, \& Lin, 2020).

\section{Current study}

The current study aimed to validate the Polish version of the FCV-19S. In the beginning, after the procedure of back-translation, we examined the structure of the scale and its psychometric properties. The original one-factor structure of the scale and measurement invariance across samples, gender and age groups were tested. Then, the relationships between the fear of Covid-19 and a set of its potential sociodemographic and psychological covariates (i.e., age and gender, perceived vulnerability to the coronavirus infection, and personality traits) were established to assess validity of the measure.

It was predicted that the fear of Covid-19 would be positively related to age (Hypothesis 1), because age is one of the important predictors of a severe course of the disease and in past studies it was positively related to the FCV-19S scores (de Leo \& Trabucchi, 2020; Meng et al., 2020). We also predicted the positive relationship between subjective vulnerability to Covid-19 and the FCV-19S scores (Hypothesis 2), because the person's conviction of being or not being exposed to a severe course of the Covid-19 disease could induce more (or less) fear (Y1ldirım \& Güler, 2021). As gender differences were obtained in other studies (the FCV-19S scores were higher in women than in men; Broche-Pérez et al., 2020), we expected to replicate this result (Hypothesis 3).

Among personality traits, neuroticism was found to be associated with the FCV-19S scores (Kroencke et al., 2020). Neuroticism (i.e., emotional lability and stress reactivity) is a trait which predisposes people to experience negative affect, and, more specifically, fear and anxiety. It has been postulated that the more neuroticism predominates as a central aspect of personality, the more threat will be perceived in a variety of situations (Reynauld et al., 2012). Negative emotional reactions in individuals high in neuroticism are typically triggered by stressors such as threat and uncertainty (Lahey, 2009). Such emotional feelings are the bread and butter of pandemic times. Studies carried out during the time of Covid-19 found that people high in neuroticism worried more about disease-related information to which they reacted with more negative affect (Kroencke et al., 2020). Thus, a positive relationship between levels of neuroticism and the FCV-19S was anticipated (Hypothesis 4). 
162 Covid-19 would be associated with preventive behavior during the pandemic. Fear and anxiety 163 are unpleasant emotions which have a negative impact on well-being and are strongly associated 164 with psychopathology (e.g., Alyami et al., 2020). Prolonged experiencing of strong negative 165 emotions, especially in individuals with risk factors, can easily lead to many maladaptive results, 166 which are broadly described in the literature, also in the context of the pandemic (e.g., Li et al.,

167 168 169

170

171

172

173

174

175

176

177

178

179

180

181

182

183

184

185

186

187

188

189

190 2020). However, from the evolutionary point of view, fear is adaptive as it mobilizes individuals to cope with threats (Nesse, 1990). Thus, during the pandemic, fear can be a factor which can reduce the propensity for risky behavior and boost people's motivation to protect themselves. Indeed, several studies gave evidence of the positive role of the fear of Covid-19 in taking preventive behavior (e.g., Wise et al., 2020). For example, a study by Harper et al. (2020) showed that the fear of Covid-19 was the only predictor of behavior change related to preventive behavior during the pandemic. Thus, taking into account the results of the past studies (Ahorsu et al., 2020a; Blagov, 2020; Bogg \& Milad, 2020; Zettler et al., 2020), we hypothesized that the FCV-19S scores would be positively related to preventive behavior during the Covid-19 pandemic (Hypothesis 5).

\section{Materials \& Methods}

\section{Participants ( $\mathbf{N}=\mathbf{7 0 8})$}

The data from the two samples were used. It was motivated by the need to obtain a large sample to perform the CFA on the FCV-19S scores. The data from both samples were collected during the same phase of the epidemic (May and June 2020) and the same procedure was used. Sample 1 consisted of 383 participants (209 females - 54.6\%; age $M=31.4, S D=11.6$ ) from the general Polish population. Seventy-eight persons $(20.4 \%)$ declared that they thought they might be at high risk for complications while developing Covid-19. The participants differed in level of education (secondary - 162 persons, Bachelor's degree - 63 persons, Master's degree - 158 persons), marital status (single - 153 participants, in relationship - 230 participants) and employment (employed - 242 participants, not employed - 141 participants).

Sample 2 consisted of 325 persons (198 females - 60.9\%; age $M=35.4, S D=12.8$ ) from the general Polish population. Seventy-nine participants $(24.3 \%)$ declared that they thought they might be at high risk for complications while developing Covid-19. The participants differed in 
191 level of education (secondary - 94 participants, Bachelor's degree - 47 participants, Master's

192 degree - 184 participants), marital status (single - 104 participants, in relationship - 195

193 participants, other - 26 participants) and employment (employed - 208 participants, not employed

$194-117$ participants).

\section{Instruments}

196 Samples 1 and 2

197 The Fear of Covid-19 was measured with the Polish version of the Fear of COVID-19 Scale 198 (FCV-19S; Ahorsu et al., 2020a), a seven-item measure with answers on a 5-point scale (1199 strongly disagree, 5-strongly agree). The questionnaire was translated from English into Polish 200 independently by two bilingual (Polish and English) researchers, whose native language was 201 Polish. The blind back-translation into English was done by another bilingual (Polish and 202 English) scholar who was not involved in the initial translation. Then, the back translation was 203 compared with the English version of the FCV-19S by a professional translator, and it was 204 confirmed that the meaning of the translated Polish version of the FCV-19S was congruent with 205 the meaning of the English version.

206 Subjective vulnerability to the Covid-19 infection was measured with one item prepared for this 207 study (“Assess your susceptibility to coronavirus infection [related to age, health status, etc.]”). 208 The participants answered using a 101-point scale (0-very low susceptibility, 100-very high 209 susceptibility).

210 Subjective health situation in the context of the coronavirus pandemic was measured with the 211 question "Do you think you are at high risk for complications if you develop Covid-19"? with 212 the answers yes/not.

213 Sample 1

214 Engagement in preventive behavior during the pandemic was measured with four items prepared 215 for this study by the authors: "I am trying to reduce the chance of being contracted with the 216 coronavirus", "I put a lot of effort into ensuring the safety of myself and my loved ones during 217 the pandemic", "I try to respect the recommendations of medical authorities regarding behavior 218 during the pandemic", "I accept most of the bans and orders introduced by the authorities to stop 219 the pandemic". The participants responded using a 5-point scale (1-strongly disagree, 5-strongly 220 agree). The scores were averaged across the items (in the current study: $\alpha=.86$ ).

221 Sample 2 
222 Personality traits. Personality traits were assessed using the short version of the Polish 223 adaptation of the International Personality Item Pool-Big Five-20 questionnaire (IPIP-BFM-20;

224 Topolewska et al., 2014). This twenty-item instrument assesses the Big Five personality traits (in 225 the current study: extraversion, $\alpha=.87$, agreeableness, $\alpha=.70$, conscientiousness, $\alpha=.76$, 226 neuroticism, $\alpha=.75$, and intellect, $\alpha=.66$ ) with answers on a 5-point scale (1-very inaccurate, 5 227 very accurate).

228 Preventive behaviors during the pandemic were measured with three questions prepared for this 229 study by the authors ("Do you maintain a distance/isolate yourself from others?", "Do you try to 230 wash your hands more often?”, “Do you disinfect objects, e.g., door handles, a smartphone?").

231 These questions are linked to three important recommendations during the pandemic: social 232 distancing/isolation, hand hygiene, and environmental cleaning/disinfection. The participants 233 answered the questions using a 101-point scale (0-definitely not, 100-definitely yes). The scores 234 on these three dimensions were used as indicators of engagement in preventive behavior.

\section{Procedure}

The participants were recruited using online advertisements in social media (Facebook, institutional websites and Internet forums). The content of the advertisements included a link to our online study with psychological questionnaires. The two separate surveys were completed online from May $15^{\text {th }}$ to June $15^{\text {th }} 2020$ (Survey 1 ) and from May $15^{\text {th }}$ to June $1^{\text {st }} 2020$ (Survey 2). During that period, there were about 12,000 confirmed cases of the disease in Poland (about 30,000 cumulative cases), and about 1250 cumulative death cases. The country was operating in lockdown. However, gradual relaxation in lockdown started from the end of May.

244 aims of each study were presented to participants at the beginning of both surveys. They were 245 also ensured that the survey was anonymous and no personal data were collected. Written 246 informed consent was obtained from all participants electronically before data collection. They 247 were asked to confirm acceptance for participation in the survey by ticking the boxes provided. 248 After that, participants provided sociodemographic information and completed the 249 questionnaires. Study 1 and Study 2 included several other measures not related to the current 250 study. The data for the present study are available as supplementary material. Both surveys were 251 approved by the Ethics Committee of the University of Silesia in Katowice (KEUS.34/04.2020, KEUS.35/04.2020). 


\section{Statistical analyses}

254 Before the analyses, the data were examined to check for missing values and normality.

255 No missing data were found. The structure of the Polish version of the FCV-19 scale was

256 investigated using confirmatory factor analysis (CFA). The CFA and invariance analyses were

257 performed in the conjoint sample, using the JASP (version 0.14) software. The mean- and

258 variance-adjusted weighted least squares (WLSMV) procedure that does not assume the data are

259 normally distributed was used (see Brown, 2006). The method uses diagonally weighted least

260 squares (DWLS) to estimate the model parameters, the full weight matrix to compute robust

261 standard errors, and a mean- and variance-adjusted test statistics. This estimation method was

262 used because the FCV-19S utilizes a 5-point Likert-type scale, thus the scores can be treated as

263 ordinal ones. To evaluate the fit of the model, the selected fit indices (which are not related to the 264 sample size; West, Taylor \& Wu, 2012) were used. The value of the root mean square error of 265 approximation (RMSEA) below 0.08 was treated as representing a sufficient fit and below 0.05 266 as representing a good fit (MacCallum, Browne \& Suragawa, 1996). The comparative fit index 267 (CFI) value and the Ticker-Lewis index (TLI) value above 0.95 were interpreted as showing a 268 good fit and above 0.90 as showing an acceptable fit (Hu \& Bentler, 1999; Schumacker \& 269 Lomax, 2010). Following the recommendations (MacCallum et al., 1996, p.137, Curran et al., 270 2003), the $90 \%$ confidence interval (CI) for the RMSEA was reported, because it enables testing 271 hypotheses of close and not-close fit.

272 To test for measurement invariance across samples, gender, and age groups, a series of 273 multiple group CFA analyses (MGCFA) was performed, in the sequence with increasingly more 274 restrictions on the parameters. Configural invariance means that the groups have the same CFA 275 structure. When metric invariance was checked, the factor loadings were constrained to be equal 276 across the groups. For scalar invariance, the factor loadings and means of the items were 277 constrained to be equal. For strict (i.e., construct-level) invariance, residual variances and 278 residual covariances were additionally constrained to be equal across the groups. Following the 279 recommendation of Cheung and Rensvold (2002) that a single standard should be used to test 280 model fit and measurement invariance, the differences in the fit indices (i.e., RMSEA, CFI and 281 McDonald Fit Index) for constrained and unconstrained models were examined. Each model was 282 compared to the baseline (or previous) model. The differences in the fit measures were analyzed. 283 The criteria recommended by Cheung and Rensvold (2002, p. 251) and Chen (2007, p. 501) were 
284 applied: the hypothesis of invariance was supported when $\Delta \mathrm{CFI} \leq-0.01, \Delta \mathrm{McD}$ onald Fit Index $285 \leq-.02$, and $\triangle$ RMSEA $<.015$.

286 The remaining analyses, i.e., reliability analysis, correlations between the FCV-19S and 287 other variables (the IPIP-BFM-20 subscales, susceptibility to Covid-19, age and engagement in 288 preventive behavior), as well as testing for differences between independent groups (the Student 289 t-test and the Mann-Whitney $U$ test) were performed in both samples separately, with the use of 290 the SPSS (version 26) software.

\section{Results}

292 Internal consistency and descriptive statistics

The Polish translation of the items of the FCV-19S with their item-total correlations and Cronbach's alphas in both samples is shown in Table 1. Internal consistency of the FCV-19S was found to be good in both samples (alpha .89 and .85). The descriptive statistics in Sample 1 and Sample 2 were as follow: $\mathrm{M}=1.99, \mathrm{SD}=.73$, skewness .78 , kurtosis .48 , and $\mathrm{M}=1.99, \mathrm{SD}=.71$, skewness .77 , kurtosis .56 , respectively.

298

299

300

301

302

303

304

305

306

307

308

309

310

311

312

313

\section{Dimensionality and measurement invariance}

The CFA showed that a one-dimensional model has adequate fit $\left(\chi^{2}=70.75, \mathrm{df}=14, \mathrm{p}<.001\right.$ RMSEA $=0.067,90 \%$ CI $[0.059,0.094], \mathrm{CFI}=0.977, \mathrm{TLI}=0.965, \mathrm{GFI}=0.986)$. The chi-square test was significant, which is not desirable. However, this test is sensitive to sample size, meaning that significant results are usually obtained for larger samples (Kline, 1998). As our sample was large $(\mathrm{N}=708)$, it could be the reason of this result.

Measurement invariance (configural, metric, scalar and strict) was tested across the study samples, gender (male, female) and age groups. The results are shown in Table 2. The MGCFA showed adequate fit for the one-factor model in both Sample $1\left(\chi^{2}=26.18, \mathrm{df}=14, \mathrm{p}=0.02\right.$, RMSEA $=0.05, \mathrm{CFI}=0.99, \mathrm{GFI}=0.99)$ and Sample $2\left(\chi^{2}=15.72, \mathrm{df}=14, \mathrm{p}=0.33, \mathrm{RMSEA}=0.02\right.$, $\mathrm{CFI}=1.00, \mathrm{GFI}=0.99)$. The results for gender showed a good fit for the model in both male $\left(\mathrm{N}=301, \chi^{2}=24.04, \mathrm{df}=14, \mathrm{p}=0.05, \mathrm{RMSEA}=0.05, \mathrm{CFI}=0.98, \mathrm{GFI}=0.98\right)$ and female $(\mathrm{N}=407$, $\left.\chi^{2}=53.6, \mathrm{df}=14, \mathrm{p}<0.001, \mathrm{RMSEA}=0.08, \mathrm{CFI}=0.97, \mathrm{GFI}=0.98\right)$ groups. The analyses performed in the two age groups separately also revealed the appropriate fit in younger $\left(\mathrm{N}=358, \chi^{2}=37.64\right.$, $\mathrm{df}=14, \mathrm{p}<0.001, \mathrm{RMSEA}=0.07, \mathrm{CFI}=0.98, \mathrm{GFI}=0.98)$ and older $\left(\mathrm{N}=350, \chi^{2}=34.53, \mathrm{df}=14\right.$, $\mathrm{p}<0.001, \mathrm{RMSEA}=0.06, \mathrm{CFI}=0.99, \mathrm{GFI}=0.99)$ groups. Thus, the criteria for configural 
314 invariance (i.e., one-factor structure) were met. The comparison of the relative fit of the nested 315 models showed that also the criteria for metric invariance (i.e., invariant factor loadings), scalar 316 invariance (i.e., invariant intercepts) and strict (construct-level) invariance were met for all

317 models tested (see Table 2).

318 Validity of the scale

319 As predicted, gender was associated with the FCV-19S scores in both samples. The fear 320 of Covid-19 was significantly higher in women than in men (Sample 1, women $\mathrm{M}=2.16$ men $321 \mathrm{M}=1.78, \mathrm{t}=5.39, \mathrm{df}=381, \mathrm{p}<.001$, Cohen's $\mathrm{d}=.55,95 \%$ CI $[.35, .76]$; Sample 2, women $\mathrm{M}=2.14$, 322 men $\mathrm{M}=1.76, \mathrm{t}=4.79, \mathrm{df}=323, \mathrm{p}<.001$, Cohen's $\mathrm{d}=.54,95 \% \mathrm{CI}[.32, .77])$. There were also 323 significant differences between sub-groups of people who declared belonging to the group of 324 people at high risk for complications while developing Covid-19 (Sample 1, belonging: Mean 325 rank $=236.0$, not belonging Mean rank=180.7, $\mathrm{U}=8462, \mathrm{p}<.001, \eta^{2}=.04$; Sample 2, belonging: Mean rank=200.8, not belonging Mean rank=150.8, $\mathrm{U}=6729, \mathrm{p}<.001, \eta^{2}=.05$ ). As predicted, the participants at high risk for complications had higher scores on the FCV-19S in both samples. Zero-order correlations between the FCV-19S scores and age, subjective vulnerability to the disease, personality traits and protective behaviors during the pandemic are shown in Table 3 and Table 4. As was hypothesized, the FCV-19S scores correlated positively with age (in Sample $1 \mathrm{r}=.22, \mathrm{p}<0.05$, in Sample $2 \mathrm{r}=.19, \mathrm{p}<0.05$ ) and subjective vulnerability (i.e., susceptibility) to Covid-19 in both samples (in Sample $1 \mathrm{r}=.36, \mathrm{p}<0.05$, in Sample $2 \mathrm{r}=.39, \mathrm{p}<0.05$ ). The correlations between personality traits and the fear of Covid-19 were also in line with the expectations. The FCV-19S scores correlated positively with Neuroticism $(\mathrm{r}=.28, p<.05)$ and there were no associations between the FCV-19S scores and Conscientiousness, Agreeableness or Extraversion. The fear of Covid-19 was also negatively related to Intellect $(\mathrm{r}=-.16, p<.05)$, which was not anticipated. However, this relationship was weaker than the predicted one. Thus, the hypotheses $\mathrm{H} 1-\mathrm{H} 4$ received support.

The expected positive relationships between the FCV-19S scores and the declared preventive behaviors during the pandemic were obtained in both samples. In Sample 1, the FCV19S scores correlated positively with the indicator of behavioral compliance with pandemic measures $(r=.34, p<0.05)$. In Sample 2, positive correlations between the FCV-19S and three kinds of behavior, i.e. social distancing $(\mathrm{r}=.34, \mathrm{p}<0.05)$, hand hygiene $(\mathrm{r}=.29, \mathrm{p}<0.05)$, and disinfecting things $(r=.36, p<0,05)$ were observed. These results supported Hypothesis 5 . 


\section{Discussion}

346 In this study, the structure and psychometric properties of the Polish version of the FCV-

347 19S were examined. Moreover, relationships between the fear of Covid-19 and a set of socio-

348 demographic and individual variables were established. The issue how to measure such emotions

349 as fear during the pandemic seems very important as the Covid-19 pandemic is far from over.

350 The FCV-19S is one of the questionnaires developed at the beginning of the pandemic crisis to

351 measure negative emotions which can occur in this new and threatening situation. The measure

352 is short and simple to use and has been translated into about twenty languages so far. The Polish

353 version of this questionnaire showed a clear factorial structure and good psychometric properties.

354 The one-factor model fits the data well.

355 The results of the analyses showed measurement invariance across samples, gender and 356 age groups. The configural invariance means that the participants (from Sample 1 and Sample 2, 357 men and women, older and younger) conceptualize the construct measured by the FCV-19S in 358 the same way. Metric invariance signifies that the factor loadings are equal across these groups.

359 Thus, cross-group comparisons can be performed. Scalar invariance means that the vectors of 360 item intercepts are also invariant across the groups, which is important when the latent means are 361 compared. Scalar invariance across the samples was only partially confirmed ( $\triangle \mathrm{RMSEA}$ was 362 under the cut-off level), but it received full support for gender and age groups. Thus, it can be 363 assumed that the criteria for strong factorial invariance are met, which enables the comparison of 364 latent means across gender and age groups (Cheung \& Rensvold, 2002, p. 238). The hypothesis 365 of construct-level (strict) invariance was also supported so that comparisons of correlations 366 between the fear of Covid-19 and other variables are possible across the groups (see Cheung \& 367 Rensvold, 2002).

368 The results of the current study revealed positive relationships between the levels of the 369 fear of Covid-19 and age, gender and subjective vulnerability to the disease. Among personality 370 traits, the FCV-19S scores correlated with neuroticism. These relationships are congruent with 371 our predictions. Therefore, the results of the current study provide evidence about the validity of 372 the Polish version of the FCV-19S. It seems important for scientists and practitioners to predict 373 which individuals can be prone to experience higher levels of fear of the coronavirus in the 374 pandemic situation, as this kind of fear can have strong consequences, which are important from 375 both individual and social points of view. Our results have shown that older individuals, women, 
376 people who feel vulnerable, and those higher in neuroticism can develop higher levels of the fear 377 of Covid-19, with all the consequences it implies. These findings are in line with other studies 378 (e.g., Carvalho et al., 2020).

379 Taking preventive actions which have the potential to slow the spread of an infectious 380 disease seems particularly important during an epidemic. In the case of the Covid-19 pandemic, 381 the lack of effective therapies, relatively high infectiousness, the presence of asymptomatic cases 382 and the anticipated long duration of the pandemic make it even more important to make people 383 adhere strictly to many pandemic rules. Negative emotions triggered by the pandemic situation

384

385

386

387

388

389

390

391

392

393

394

395

396

397

398

399

400

401

402

403

404

405 can impact obedience. Correlation analysis revealed positive relationships between the FCV-19S scores and preventive behavior in both samples. The associations of the FCV-19S scores with the scores on the scale measuring engagement in preventive behavior during the pandemic (i.e., accepting preventive measures, respecting recommendations and trying to reduce the probability of infection) were found in Sample 1. The relationships between the fear of Covid-19 and taking preventive actions during the pandemic (i.e., social distancing/isolation, hand hygiene and cleaning/disinfecting) were obtained in Sample 2. Generally, people who felt more fearful about the coronavirus declared stronger engagement in preventive behavior. This result provides the initial evidence of the predictive value of the Polish version of the FCV-19S.

Our study has some limitations. First, our participants were relatively young. Therefore, the majority of them scored rather low on the FCV-19S, which could impact the results. Second, only self-report measures were used. Self-reports may not be the optimal source of data, particularly in the case of preventive behavior. Third, the cross-sectional study design makes drawing causal inferences difficult. Fourth, by using an online survey, our sample was restricted to people with access to the Internet. Nevertheless, the current data enable the conclusion that the Polish version of the fear of Covid-19 scale is a reliable tool for the measurement of fear of being contracted during the coronavirus pandemic.

\section{Conclusions}

The main aim of the study was to examine the structure and psychometric properties of the Polish version of the FCV-19 scale. We tested the original structure and measurement invariance across samples, gender and age groups. The scale showed a clear one-factor structure and good psychometric properties The fear of Covid-19 can have strong clinical consequences, 
406 so it is particularly important for scientists and practitioners to predict which individuals can be 407 prone to experience it. Our results have shown that older individuals, women, people who feel 408 vulnerable, and those higher in neuroticism can develop higher levels of the fear of Covid-19. 409 Considering that participants in the study were relatively young, and the majority of them scored 410 rather low on the FCV-19S, the experiences of fear of Covid-19 in the elderly require further 411 investigation. Nevertheless, the obtained data enable the conclusion that the Polish version of the 412 fear of Covid-19 scale is a reliable tool for the measurement of fear of being contracted during 413 the coronavirus pandemic.

\section{References}

Abdelrahman M. 2020. Personality Traits, Risk Perception, and Protective Behaviors of Arab Residents of Qatar During the COVID-19 Pandemic. International Journal of Mental Health and Addiction, 1-12. DOI: 10.1007/s11469-020-00352-7

Haktanir A, Seki T, Dilmaç B. 2020. Adaptation and evaluation of Turkish version of the fear of COVID-19 Scale. Death Studies. DOI: 10.1080/07481187.2020.1773026

Ahmed MZ, Ahmed O, Aibao Z, Hanbin S, Siyu L, Ahmad A. 2020. Epidemic of COVID-19 in China and associated Psychological Problems. Asian Journal of Psychiatry, 51, 102092. DOI: 10.1016/j.ajp.2020.102092

Ahorsu DK, Imani V, Lin CY, Timpka T, Broström A, Updegraff JA, ... \& Pakpour AH. 2020 b. Associations Between Fear of COVID-19, Mental Health, and Preventive Behaviours Across Pregnant Women and Husbands: An Actor-Partner Interdependence Modelling. International Journal of Mental Health and Addiction, 1-15. DOI: 10.1007/s11469-02000340-X

Ahorsu DK, Lin CY, Imani V, Saffari M, Griffiths MD, Pakpour AH. 2020a. The Fear of COVID-19 Scale: Development and Initial Validation. International Journal of Mental Health and Addiction, 1-9. DOI: 10.1007/s11469-020-00270-8

Alyami M, Albuquerque J, Krägeloh C, Alyami H, Henning, M. 2020. Effects of Fear of COVID-19 on Mental Well-Being and Quality of Life: A path analysis. International Journal of Mental Health and Addiction. Research Square Preprint. Available at 
436

437

438

439

440

441

442

443

444

445

446

447

448

449

450

451

452

453

454

455

456

457

458

459

460

461

462

463

464

465

466

https://www.researchsquare.com/article/rs-59161/v1 (accessed: 20.11.2020). DOI:

$10.1007 / \mathrm{s} 11469-020-00316-\mathrm{x}$

Aschwanden D, Strickhouser JE, Sesker AA, Lee JH, Luchetti M, Stephan Y, Sutin AR Terracciano A. 2020. Psychological and Behavioural Responses to Coronavirus Disease 2019: The Role of Personality. European Journal of Personality. DOI: 10.1002/per.2281

Asmundson GJG, Taylor S. 2020. Coronaphobia: Fear and the 2019-nCoV outbreak. Journal of Anxiety Disorders, 70, 102196. DOI: 10.1016/j.janxdis.2020.102196

Barrios I, Rios-Gonzalez I, O’Higgins M, Gonzalez I, Garcia O, Diaz NR, Castaldelli-Maia JM, Ventriglio A, Torales J. 2020. Psychometric properties of the Spanish version of the Fear of COVID-19 Scale (FCV-19S). Research Square Preprint. Available at https://www.researchsquare.com/article/rs-33345/v1 (accessed: 25.11.2020). DOI: 10.21203/rs.3.rs-33345/v1

Bharatharaj J, Alyami M, Henning MA, Alyami H, Krägeloh CU. 2020. Tamil version of the Fear of COVID-19 Scale. Research Square Preprint. Available at https:/www.researchsquare.com/article/rs-40914/v1 (accessed: 25.11.2020). DOI: 10.21203/rs.3.rs-40914/v1

Bitan DT, Grossman-Giron A, Bloch Y, Mayer Y, Shiffman N, Mendlovic S. 2020. Fear of COVID- 19 scale: psychometric characteristics, reliability and validity in the Israeli population. Psychiatry Research, 289, 113100. DOI: 10.1016/j.psychres.2020.113100

Blagov PS. 2020. Adaptive and Dark Personality Traits in the Covid-19 Pandemic: Predicting Health-behavior Endorsement and the Appeal of Public-health Messages. Social Psychological and Personality Science, 1948550620936439. DOI: $10.1177 / 1948550620936439$

Bogg T, Milad, E. 2020. Demographic, Personality, and Social Cognition Correlates of Coronavirus Guideline Adherence in a U.S. Sample. PsyArXiv Preprints. Available at https:/psyarxiv.com/yc2gq/ (accessed: 25.11.2020). DOI: $10.31234 /$ osf.io/yc2gq

Broche-Pérez Y, Fernández-Fleites Z, Jiménez-Puig E, Fernández-Castillo E, Rodríguez-Martin BC. 2020. Gender and Fear of COVID-19 in a Cuban Population Sample. International Journal of Mental Health and Addiction, 1-9. Advance online publication. Available at https://link.springer.com/article/10.1007\%2Fs11469-020-00343-8 (accessed:

25.11.2020). DOI: 10.1007/s11469-020-00343-8 
467 Brown TA. 2006. Confirmatory Factor Analysis for Applied Research. The Guildford Press, $468 \quad$ New York.

469 Browne M. 2000. Cross-validation methods. Journal of Mathematical Psychology, 44(1), 108470 132. DOI: $10.1006 /$ jmps.1999.1279

471 Carpenter CJ. 2010. A meta-analysis of the effectiveness of health belief model variables in 472 predicting behavior. Health Communication, 25(8), 661-669. DOI:

$473 \quad 10.1080 / 10410236.2010 .521906$

474 Carvalho LF, Pianowski G, Gonçalves AP. 2020. Personality differences and COVID-19: are 475 extroversion and conscientiousness personality traits associated with engagement with

476 477 containment measures? Trends in Psychiatry and Psychotherapy, 42(2), 179-184. DOI:

478 $10.1590 / 2237-6089-2020-0029$

Chang KC, Hou WL, Pakpour AH, Lin CY, Griffiths MD. 2020. Psychometric testing of three

479

480 COVID-19-related scales among people with mental illness. International Journal of

481 482 483 484 485 486 487 488 489 490 491

492 493 494 495 496 Mental Health and Addiction, 1-13. DOI: 10.1007/s11469-020-00361-6

Chen FF. 2007. Sensitivity of goodness of fit indexes to lack of measurement invariance. Structural Equation Modeling, 14(3), 464-504. DOI: 10.1080/10705510701301834

Cheung GW, Rensvold RB. 2002. Evaluating goodness-of-fit indexes for testing measurement invariance. Structural Equation Modeling, 9(2), 233-255. DOI: 10.1207/S15328007SEM0902_5

Chi X, Chen S, Chen Y, Chen D, Yu Q, Guo T, Cao Q, Zheng X, Huang S, Hossain M, Stubbs B, Yeung A, Zou L. 2021. Psychometric Evaluation of The Fear of COVID-19 Scale Among Chinese Population. International Journal of Mental Health and Addiction. 1-16. DOI: $10.1007 /$ s1 1469-020-00441-7.

Colizzi M, Bortoletto R, Silvestri M, Zoccante, Mondini F, Puttini E, Cainelli C, Gaudino R, Ruggeri M, Zoccante L. 2020. Medically unexplained symptoms in the times of Covid-19 pandemic: a case-report. Brain, Behavior, \& Immunity - Health. 5, 100073. DOI: 10.1016/j.bbih.2020.100073

Curran PJ, Bollen KA, Chen F, Paxton P, Kirby JB. 2003. Finite Sampling Properties of the Point Estimates and Confidence Intervals of the RMSEA. Sociological Methods \& Research, 32(2), 208-252. DOI: 10.1177/0049124103256130 
497 de Leo D, Trabucchi M. 2020. COVID-19 and the fears of Italian senior citizens. International $498 \quad J o u r n a l$ of Environmental Research and Public Health, 17 (10), 3572. DOI:

499 10.3390/ijerph17103572

500

501

502

503

504

505

506

507

508

509

510

511

512

513

514

515

516

517

518

519

520

521

522

523

524

525

Dong L, Bouey J. 2020. Public Mental Health Crisis during COVID-19 Pandemic, China. Emerging Infectious Diseases, 26(7), 1616-1618. DOI: 10.3201/eid2607.200407

Faro A, dos Santos Silva L, dos Santos DN, Feitosa ALB. 2020. Adaptação e validação da Escala de Medo da COVID-19 [Adaptation and validation of the Fear of COVID-19 Scale]. SciELO Preprints. Available at https://preprints.scielo.org/index.php/scielo/preprint/view/898 (accessed: 25.11.2020). DOI: $10.1590 /$ SciELOPreprints. 898

Friedman HS. 2000. Long-term relations of personality and health: Dynamisms, mechanisms, tropisms. Journal of Personality, 68(6), 1089-1107. DOI: 10.1111/1467-6494.00127

Harper CA, Satchell LP, Fido D, Latzman RD. 2020. Functional Fear Predicts Public Health Compliance in the COVID-19 Pandemic. International Journal of Mental Health and Addiction, 1-14. DOI: 10.1007/s11469-020-00281-5

Huarcaya-Victoria J, Villarreal-Zegarra D, Podestà A, Luna-Cuadros MA. 2020. Psychometric properties of a Spanish version of the Fear of COVID-19 Scale in general population of Lima, Peru. International Journal of Mental Health and Addiction, 1-14. DOI: 10.1007/s11469-020-00354-5

Hu LT, Bentler PM. 1999. Cutoff criteria for fit indexes in covariance structure analysis: conventional criteria versus new alternatives. Structural Equation Modeling: A Multidisciplinary Journal, 6(1), 1-55. DOI: 10.1080/10705519909540118

Jensen-Campbell LA, Graziano WG. 2001. Agreeableness as a moderator of interpersonal conflict. Journal of Personality, 69(2), 323-362. DOI: 10.1111/1467-6494.00148

Kline RB. 1998. Principles and Practice of Structural Equation Modeling. The Guilford Press, London.

Kuper-Smith B, Doppelhofer L, Oganian Y, Rosenblau G, Korn C. 2020. Optimistic beliefs about the personal impact of COVID-19. PsyArXiv Preprints. Available at https://psyarxiv.com/epcyb/ (accessed: 25.11.2020). DOI: 10.31234/osf.io/epcyb 
526 Kroencke L, Geukes K, Utesch T, Kuper N, Back M. 2020. Neuroticism and Emotional Risk 527 During the Covid-19 Pandemic. Journal of Research in Personality, 89:104038. DOI: $528 \quad 10.1016 /$ j.jp. 2020.104038 .

529 Lahey BB. 2009. Public health significance of neuroticism. American Psychologist, 64, 241-256. 530 DOI: $10.1037 / \mathrm{a} 0015309$

531 Li JB, Yang A, Dou K, Cheung RYM. 2020. Self-Control Moderates the Association Between 532 Perceived Severity of Coronavirus Disease 2019 (COVID-19) and Mental Health 533 534 535 536 537 538 Problems Among the Chinese Public. International Journal of Environmental Research and Public Health, 17(13), 4820. DOI: 10.3390/ijerph17134820

Lin CY. 2020. Social reaction toward the 2019 novel coronavirus (COVID-19). Social Health and Behavior. 3(1), 1-2. DOI: 10.4103/SHB.SHB_11_20

MacCallum RC, Browne MW, Sugawara HM. 1996. Power analysis and determination of sample size for covariance structure modeling. Psychological Methods, 1(2), 130-149. DOI: $10.1037 / 1082-989 X \cdot 1.2 .130$

Mahmood QK, Jafree SR, Qureshi WA. 2020. The psychometric validation of FCV19S in Urdu and socio-demographic association with fear in the people of the Khyber Pakhtunkhwa (KPK) province in Pakistan. International Journal of Mental Health and Addiction, 1-11. DOI: $10.1007 / \mathrm{s} 11469-020-00371-4$

Mailliez M, Griffiths MD, Carre A. 2020. Validation of the French version of the Fear of COVID-19 Scale and its associations with depression, anxiety and differential emotions. Research Square Preprint. Available at https://www.researchsquare.com/article/rs46616/v1 (accessed: 25.11.2020). DOI: 10.21203/rs.3.rs-46616/v1

Martínez-Lorca M, Martínez-Lorca A, Criado-Álvarez JJ, Armesilla MDC. 2020. The Fear of COVID-19 Scale: Validation in Spanish university students. Psychiatry Research, 293, 113350. DOI: 10.1016/j.psychres.2020.113350

Masuyama A, Shinkawa H, Kubo T. 2020. Validation and Psychometric Properties of the Japanese Version of the Fear of COVID-19 Scale Among Adolescents. International Journal of Mental Health and Addiction, 1-11. DOI: 10.1007/s11469-020-00368-Z

Meng H, Xu Y, Dai J, Zhang Y, Liu B, Yang H. 2020. Analyze the psychological impact of COVID-19 among the elderly population in China and make corresponding suggestions. Psychiatry Research, 289, 112983. DOI: 10.1016/j.psychres.2020.112983 
557 Milne S, Sheeran P, Orbell S. 2000. Prediction and intervention in health-related behavior: A

558

559

560

561

562

563

564

565

566

567

568

569

570

571

572

573

574

575

576

577

578

579

580

581

582

583

584

585

586

587

meta-analytic review of protection motivation theory. Journal of Applied Social Psychology, 30(1), 106-143. DOI: 10.1111/j.1559-1816.2000.tb02308.x

Nesse RM. 1990. Evolutionary explanations of emotions. Human Nature, 1(3), 261-289. DOI: 10.1007/BF02733986

Ornell F, Schuch JB, Sordi AO, Kessler FHP. 2020. "Pandemic fear" and COVID-19: mental health burden and strategies. Brazilian Journal of Psychiatry, 42(3), 232-235. DOI: $10.1590 / 1516-4446-2020-0008$

Pang NTP, Kamu A, Hambali NLB, Mun HC, Kassim MA, Mohamed NH, Ayu F, Rahim SSSA, Omar A, Jeffree MS. 2020. Malay Version of the Fear of COVID-19 Scale: Validity and Reliability. International Journal of Mental Health and Addiction. DOI: 10.1007/s11469020-00355-4

Pakpour AH, Griffiths MD, Lin CY. 2020. Assessing psychological response to the COVID-19: the fear of COVID-19 scale and the COVID stress scales. International Journal of Mental Health and Addiction, 1-4. DOI: 10.1007/s11469-020-00334-9

Perz CA, Lang BA, Harrington R. 2020. Validation of the Fear of COVID-19 Scale in a US college sample. International Journal of Mental Health and Addiction. Advance online publication. Available at https://www.ncbi.nlm.nih.gov/pmc/articles/PMC7315905 (accessed: 25.11.2020). DOI: 10.1007/s11469-020-00356-3

Peteet JR. 2020. COVID-19 Anxiety. Journal of Religion and Health, 59(5), 2203-2204. DOI: $10.1007 / \mathrm{s} 10943-020-01041-4$

Reynaud E, El Khoury-Malhame M, Rossier J, Blin O, Khalfa S. 2012. Neuroticism modifies psychophysiological responses to fearful films. PLoS ONE, 7(3), e32413. DOI:

10.1371/journal.pone.0032413

Reznik A, Gritsenko V, Konstantinov V, Khamenka N, Isralowitz R. 2020. COVID-19 fear in Eastern Europe: Validation of the Fear of COVID-19 Scale. International Journal of Mental Health and Addiction, 1-6. Advance online publication. Available at https://www.ncbi.nlm.nih.gov/pmc/articles/PMC7217343/ (accessed: 25.11.2020). DOI: $10.1007 / \mathrm{s} 11469-020-00283-3$

Sakib N, Mamun MA, Bhuiyan AKMI, Hossain S, Mamun FA, Hosen I, Abdullah AH, Sarker MA, Mohiuddin MS, Rayhan I, Hossain M, Sikder MT, Gozal D, Muhit MA, Islam SMS, 
588

589

590

591

592

593

594

595

596

597

598

599

600

601

602

603

604

605

606

607

608

609

610

611

612

613

614

615

616

617

Griffiths MD, Pakpour AH. 2020. Psychometric validation of the Bangla Fear of COVID19 Scale: Confirmatory factor analysis and Rasch analysis. International Journal of Mental Health and Addiction. Advance online publication. Available at https://psycnet.apa.org/record/2020-32796-00 (accessed: 25.11.2020). DOI:

10.1007/s11469-020-00289-x

Satici B, Gocet-Tekin E, Deniz ME, Satici SA. 2020. Adaptation of the Fear of COVID-19

Scale: Its Association with Psychological Distress and Life Satisfaction in Turkey. International Journal of Mental Health and Addiction, 1-9. DOI: 10.1007/s11469-02000294-0

Schumacker RE, Lomax RG. 2010. A beginner's guide to structural equation modeling (3rd ed.). New York, NY: Routledge Academic.

Shaw S. 2020. Hopelessness, helplessness and resilience: The importance of safeguarding our trainees' mental wellbeing during the COVID-19 pandemic. Nurse Education in Practice, 44, 102780. DOI: 10.1016/j.nepr.2020.102780

Shook N, Sevi B, Lee J, Fitzgerald HN, Oosterhoff B. 2020. Who's listening? Predictors of concern about COVID-19 and preventative health behaviors. PsyArXiv Preprints. Available at https://psyarxiv.com/c9rfg/ (accessed: 25.11.2020). DOI: 10.31234/osf.io/c9rfg

Stănculescu E. 2021. Fear of COVID-19 in Romania: Validation of the Romanian Version of the Fear of COVID-19 Scale Using Graded Response Model Analysis. International Journal of Mental Health and Addiction, 1-16. DOI:10.1007/s11469-020-00428-4

Soraci P, Ferrari A, Abbiati FA, Del Fante E, De Pace R, Griffiths Urso A. 2020. Validation and psychometric evaluation of the Italian version of the Fear of COVID-19 Scale.

International Journal of Mental Health and Addiction, 1-10. DOI: 10.1007/s11469-02000277-1

Soto CJ. 2019. How replicable are links between personality traits and consequential life outcomes? The Life Outcomes of Personality Replication Project. Psychological Science, 30, 711-727. DOI: $10.1177 / 0956797619831612$

Taylor S. 2019. The Psychology of Pandemics: Preparing for the Next Global Outbreak of Infectious Disease. Newcastle upon Tyne: Cambridge Scholars Publishing. 
618 Tett RP, Guterman HA. 2000. Situation trait relevance, trait expression, and cross-situational

619

620

621

622

623

624

625

626

627

628

629

630

631

632

633

634

635

636

637

638

639

640

641

642

643

644

645

646

647

648 consistency: Testing a principle of trait activation. Journal of Research in Personality, 34(4), 397-423. DOI: 10.1006/jrpe.2000.2292

Tian F, Li H, Tian S, Yang J, Shao J, Tian C. 2020. Psychological symptoms of ordinary Chinese citizens based on SCL-90 during the level I emergency response to COVID-19. Psychiatry Research, 288, 112992. DOI: 10.1016/j.psychres.2020.112992

Topolewska E, Skimina E, Strus W, Cieciuch J, Rowiński T. 2014. The short IPIP-BFM-20 questionnaire for measuring the Big Five. Roczniki Psychologiczne, 17(2), 385-402.

Tsipropoulou V, Nikopoulou VA, Holeva V, Nasika Z, Diakogiannis I, Sakka S, Kostikidou S, Varvara C, Spyridopoulou E, Parlapani E. 2020. Psychometric properties of the Greek version of FCV-19S. International Journal of Mental Health and Addiction. Advance online publication. Available at https://www.ncbi.nlm.nih.gov/pmc/articles/PMC7250285/ (accessed: 25.11.2020). DOI: $10.1007 / \mathrm{s} 11469-020-00319-8$

Wang D, Hu B, Hu C, Zhu F, Liu X, Zhang J, Wang B, Xiang H, Cheng Z, Xiong Y, Zhao Y, Li Y, Wang X, Peng Z. 2020. Clinical characteristics of 138 hospitalized patients with 2019 novel coronavirus-infected pneumonia in Wuhan, China. JAMA, 323(11), 1061-1069. DOI: $10.1001 /$ jama.2020.1585

West SG, Taylor AB, Wu W. 2012. Model fit and model selection in structural equation modeling. In RH Hoyle (Ed.), Handbook of Structural Equation Modeling (pp. 209-231). New York, NY: Guilford.

Winter T, Riordan B, Pakpour A, Griffiths M, Mason A, Poulgrain J, Damian S. 2020. Evaluation of the English version of the Fear of COVID-19 Scale and its relationship with behavior change and political beliefs. International Journal of Mental Health and Addiction. DOI: 10.1007/s11469-020-00342-9

Wise T, Zbozinek TD, Michelini G, Hagan CC, Mobbs D. 2020. Changes in risk perception and protective behavior during the first week of the COVID-19 pandemic in the United States. Royal Society Open Science, 7(9). DOI: 10.1098/rsos.200742

World Health Organization. 2020. Coronavirus disease (COVID-19) advice for the public 2020. Available at https://www.who.int/emergencies/diseases/novel-coronavirus-2019/advicefor-public (accessed: 20.08.2020). 
649 Xiang YT, Yang Y, Li W, Zhang L, Zhang Q, Cheung T, Ng CH. 2020. Timely mental health

650

651

652

653

654

655

656

657

658

659

660

661

662

663

664

665

care for the 2019 novel coronavirus outbreak is urgently needed. The Lancet Psychiatry, 7(3), 228-229. DOI: 10.1016/S2215-0366(20)30046-8

Yıldırım M, Güler A. 2021. Positivity explains how COVID-19 perceived risk increases death distress and reduces happiness. Personality and Individual Differences, 168, 110347. DOI: $10.1016 /$ j.paid.2020.110347

Zettler I, Schild C, Lilleholt L, Kroencke L, Utesch T, Moshagen M, Böhm R, Back M, Geukes, K. 2020. The role of personality in COVID-19 related perceptions, evaluations, and behaviors: Findings across five samples, nine traits, and 17 criteria. PsyArXiv Preprints. Available at https://psyarxiv.com/pkm2a/ (accessed: 25.11.2020). DOI: 10.31234/osf.io/pkm2a

Zhang WR, Wang K, Yin L, Zhao WF, Xue Q, Peng M, Min BQ, Tian Q, Leng HX, Du JL, Chang H, Yang Y, Li W, Shangguan FF, Yan TY, Dong HQ, Han Y, Wang YP, Cosci F, Wang HX. 2020. Mental health and psychosocial problems of medical health workers during the COVID-19 epidemic in China. Psychotherapy and Psychosomatics, 1, 1-9. DOI: $10.1159 / 000507639$

Peer) reviewing PDF | (2020:12:56304:1:0:NEW 9 Feb 2021) 


\section{Table 1 (on next page)}

Item translation and item-total correlation for the FCV-19S. 


\begin{tabular}{|c|c|c|c|c|c|c|c|c|c|c|}
\hline \multirow[b]{2}{*}{ Items } & \multicolumn{2}{|c|}{$\begin{array}{c}\text { Item-total } \\
\text { correlation } \\
\text { (corrected) } \\
\end{array}$} & \multicolumn{2}{|c|}{$\begin{array}{l}\text { Cronbach's Alpha } \\
\text { (if item deleted) }\end{array}$} & \multicolumn{2}{|c|}{ Mean (SD) total } & \multicolumn{2}{|c|}{ Mean (SD) males } & \multicolumn{2}{|c|}{$\begin{array}{l}\text { Mean (SD) } \\
\text { females }\end{array}$} \\
\hline & $\begin{array}{c}\text { Sample } \\
1 \\
(\mathrm{~N}=383 \\
)\end{array}$ & $\begin{array}{c}\text { Sample } \\
2 \\
(\mathrm{~N}=325 \\
)\end{array}$ & $\begin{array}{c}\text { Sample } \\
1 \\
(\mathrm{~N}=383 \\
)\end{array}$ & $\begin{array}{c}\text { Sample } \\
2 \\
(\mathrm{~N}=325 \\
)\end{array}$ & $\begin{array}{c}\text { Sample } \\
1 \\
(\mathrm{~N}=383 \\
)\end{array}$ & $\begin{array}{c}\text { Sample } \\
2 \\
(\mathrm{~N}=325 \\
\quad)\end{array}$ & $\begin{array}{c}\text { Sample } \\
1 \\
(\mathrm{~N}=174 \\
\quad)\end{array}$ & $\begin{array}{c}\text { Sample } \\
2 \\
(\mathrm{~N}=127 \\
)\end{array}$ & $\begin{array}{c}\text { Sample } \\
1 \\
(\mathrm{~N}=209 \\
)\end{array}$ & $\begin{array}{c}\text { Sample } \\
2 \\
(\mathrm{~N}=198 \\
)\end{array}$ \\
\hline $\begin{array}{l}1 \text { Bardzo boję się } \\
\text { koronawirusa [I am most } \\
\text { afraid of coronavirus-19] }\end{array}$ & .70 & .63 & .87 & .82 & $\begin{array}{c}2.60 \\
(1.04)\end{array}$ & $\begin{array}{c}2.72 \\
(1.15)\end{array}$ & $\begin{array}{c}2.35 \\
(0.98)\end{array}$ & $\begin{array}{c}2.46 \\
(1.15)\end{array}$ & $\begin{array}{c}2.80 \\
(1.04)\end{array}$ & $\begin{array}{c}2.89 \\
(1.12)\end{array}$ \\
\hline $\begin{array}{l}2 \text { Czuję się nieswojo gdy } \\
\text { myślę o koronawirusie [It } \\
\text { makes me uncomfortable } \\
\text { to think about coronavirus- } \\
\text { 19] }\end{array}$ & .72 & .67 & .87 & .82 & $\begin{array}{c}2.42 \\
(1.10)\end{array}$ & $\begin{array}{c}2.72 \\
(1.27)\end{array}$ & $\begin{array}{c}2.14 \\
(1.03)\end{array}$ & $\begin{array}{c}2.31 \\
(1.22)\end{array}$ & $\begin{array}{c}2.66 \\
(1.11)\end{array}$ & $\begin{array}{c}2.98 \\
(1.24)\end{array}$ \\
\hline $\begin{array}{l}3 \text { Moje dłonie stają się } \\
\text { wilgotne gdy myślę o } \\
\text { koronawirusie [My hands } \\
\text { become clammy when I } \\
\text { think about coronavirus- } \\
\text { 19] }\end{array}$ & .66 & .53 & .88 & .84 & $\begin{array}{c}1.52 \\
(0.66)\end{array}$ & $\begin{array}{c}1.35 \\
(0.72)\end{array}$ & $\begin{array}{c}1.36 \\
(0.57)\end{array}$ & $\begin{array}{r}1.26 \\
(0.62)\end{array}$ & $\begin{array}{c}1.67 \\
(0.70)\end{array}$ & $\begin{array}{c}1.41 \\
(0.77)\end{array}$ \\
\hline $\begin{array}{l}4 \text { Boję się, że stracę życie } \\
\text { z powodu koronawirusa [I }\end{array}$ & .72 & .64 & .87 & .82 & $\begin{array}{c}1.95 \\
(0.96)\end{array}$ & $\begin{array}{c}1.97 \\
(1.11)\end{array}$ & $\begin{array}{c}1.84 \\
(0.99)\end{array}$ & $\begin{array}{c}1.70 \\
(0.92)\end{array}$ & $\begin{array}{l}2.05 \\
(0.92)\end{array}$ & $\begin{array}{c}2.14 \\
(1.19)\end{array}$ \\
\hline
\end{tabular}




\begin{tabular}{|c|c|c|c|c|c|c|c|c|c|c|}
\hline $\begin{array}{l}\text { am afraid of losing my life } \\
\text { because of coronavirus-19] }\end{array}$ & & & & & & & & & & \\
\hline $\begin{array}{l}5 \text { Gdy oglądam } \\
\text { wiadomości lub historie o } \\
\text { koronawirusie w mediach } \\
\text { społecznościowych, } \\
\text { denerwuję się lub } \\
\text { niepokoję [When watching } \\
\text { news and stories about } \\
\text { coronavirus-19 on social } \\
\text { media, I become nervous } \\
\text { or anxious] }\end{array}$ & 68 & .63 & 87 & .83 & $\begin{array}{c}2.41 \\
(1.12)\end{array}$ & $\begin{array}{c}2.46 \\
(1.21)\end{array}$ & $\begin{array}{c}2.07 \\
(1.97)\end{array}$ & $\begin{array}{c}2.13 \\
(1.16)\end{array}$ & $\begin{array}{c}2.69 \\
(1.08)\end{array}$ & $\begin{array}{c}2.67 \\
(1.20)\end{array}$ \\
\hline $\begin{array}{l}6 \text { Nie mogę spać, gdyż } \\
\text { martwię się że mogę } \\
\text { złapać koronawirusa [I } \\
\text { cannot sleep because I'm } \\
\text { worrying about getting } \\
\text { coronavirus-19] }\end{array}$ & .70 & .66 & .87 & .83 & $\begin{array}{l}1.49 \\
(0.72)\end{array}$ & $\begin{array}{c}1.36 \\
(0.70)\end{array}$ & $\begin{array}{c}1.33 \\
(0.65)\end{array}$ & $\begin{array}{c}1.23 \\
(0.49)\end{array}$ & $\begin{array}{c}1.61 \\
(0.75)\end{array}$ & $\begin{array}{c}1.45 \\
(0.80)\end{array}$ \\
\hline $\begin{array}{l}7 \text { Serce wali mi jak } \\
\text { młotem gdy myślę o } \\
\text { zarażeniu się } \\
\text { koronawirusem [My heart }\end{array}$ & 68 & .64 & 87 & .83 & $\begin{array}{c}1.54 \\
(0.77)\end{array}$ & $\begin{array}{c}1.35 \\
(0.70)\end{array}$ & $\begin{array}{c}1.38 \\
(0.73)\end{array}$ & $\begin{array}{c}1.20 \\
(0.51)\end{array}$ & $\begin{array}{c}1.67 \\
(0.77)\end{array}$ & $\begin{array}{c}1.45 \\
(0.78)\end{array}$ \\
\hline
\end{tabular}




\begin{tabular}{|l|c|c|c|c|c|c|c|c|c|c|}
\hline $\begin{array}{l}\text { races or palpitates when I } \\
\text { think about getting } \\
\text { coronavirus-19] }\end{array}$ & & & & & & & & & & \\
\hline The FCV-19 Scale & - & - & .89 & .85 & 1.99 & 1.99 & 1.78 & 1.76 & 2.16 & 2.14 \\
& & & & & $(0.71)$ & $(0.73)$ & $(0.65)$ & $(0.61)$ & $(0.72)$ & $(0.76)$ \\
\hline
\end{tabular}




\section{Table 2 (on next page)}

Testing for measurement invariance across samples, gender, and age groups. 


\begin{tabular}{|c|c|c|c|c|c|}
\hline Model & RMSEA & DRMSEA & CFI & $\Delta \mathrm{CFI}$ & Invariance \\
\hline \multicolumn{6}{|c|}{ Sample invariance (Sample 1 vs. Sample 2) } \\
\hline Configural invariance & 0.061 & & 0.985 & & YES \\
\hline Metric invariance & 0.059 & -0.002 & 0.983 & -0.002 & YES \\
\hline Scalar invariance & 0.073 & 0.014 & 0.970 & -0.013 & YES/NO \\
\hline Strict invariance & 0.077 & 0.004 & 0.960 & -0.010 & YES \\
\hline \multicolumn{6}{|c|}{ Gender invariance (males vs. females) } \\
\hline Configural invariance & 0.071 & & 0.978 & & YES \\
\hline Metric invariance & 0.065 & -0.006 & 0.977 & -0.001 & YES \\
\hline Scalar invariance & 0.060 & -0.005 & 0.977 & 0.000 & YES \\
\hline Strict invariance & 0.058 & --0.002 & 0.974 & -0.003 & YES \\
\hline \multicolumn{6}{|c|}{ Age invariance $(\leq 40$ vs. $>40)$} \\
\hline Configural invariance & 0.072 & & 0.979 & & YES \\
\hline Metric invariance & 0.077 & 0.005 & 0.970 & -0.009 & YES \\
\hline Scalar invariance & 0.068 & -0.009 & 0.971 & 0.001 & YES \\
\hline Strict invariance & 0.073 & 0.005 & 0.961 & -0.01 & YES \\
\hline
\end{tabular}

1 


\section{Table 3 (on next page)}

Means, standard deviations and intercorrelations between study variables (Sample 2). 


\begin{tabular}{|l|c|c|c|c|c|}
\hline & $\mathrm{M}$ & $\mathrm{SD}$ & $(1)$ & $(2)$ & $(3)$ \\
\hline (1) Fear of Covid-19 & 1.99 & .71 & - & & \\
\hline (2) Age & 31.37 & 11.60 & $\mathbf{. 2 2 0 ( . 0 0 0 )}$ & - & \\
\hline (3) Vulnerability & 35.89 & 25.3 & $\mathbf{. 3 5 7 ( . 0 0 0 )}$ & $\mathbf{. 2 6 7 ( . 0 0 0 )}$ & - \\
\hline $\begin{array}{l}\text { (4) Engagement in } \\
\text { preventive behavior }\end{array}$ & 3.94 & .85 & $\mathbf{. 3 3 5 ( . 0 0 0 )}$ & $-.028(.58)$ & $\mathbf{. 1 8 7 ( . 0 0 0 )}$ \\
\hline
\end{tabular}

2

3 Note. Significance level in parentheses. Significant correlation coefficients $(p<.05)$ in bold. $N=385$.

4

5 


\section{Table 4 (on next page)}

Means, standard deviations and intercorrelations between study variables (Sample 1). 


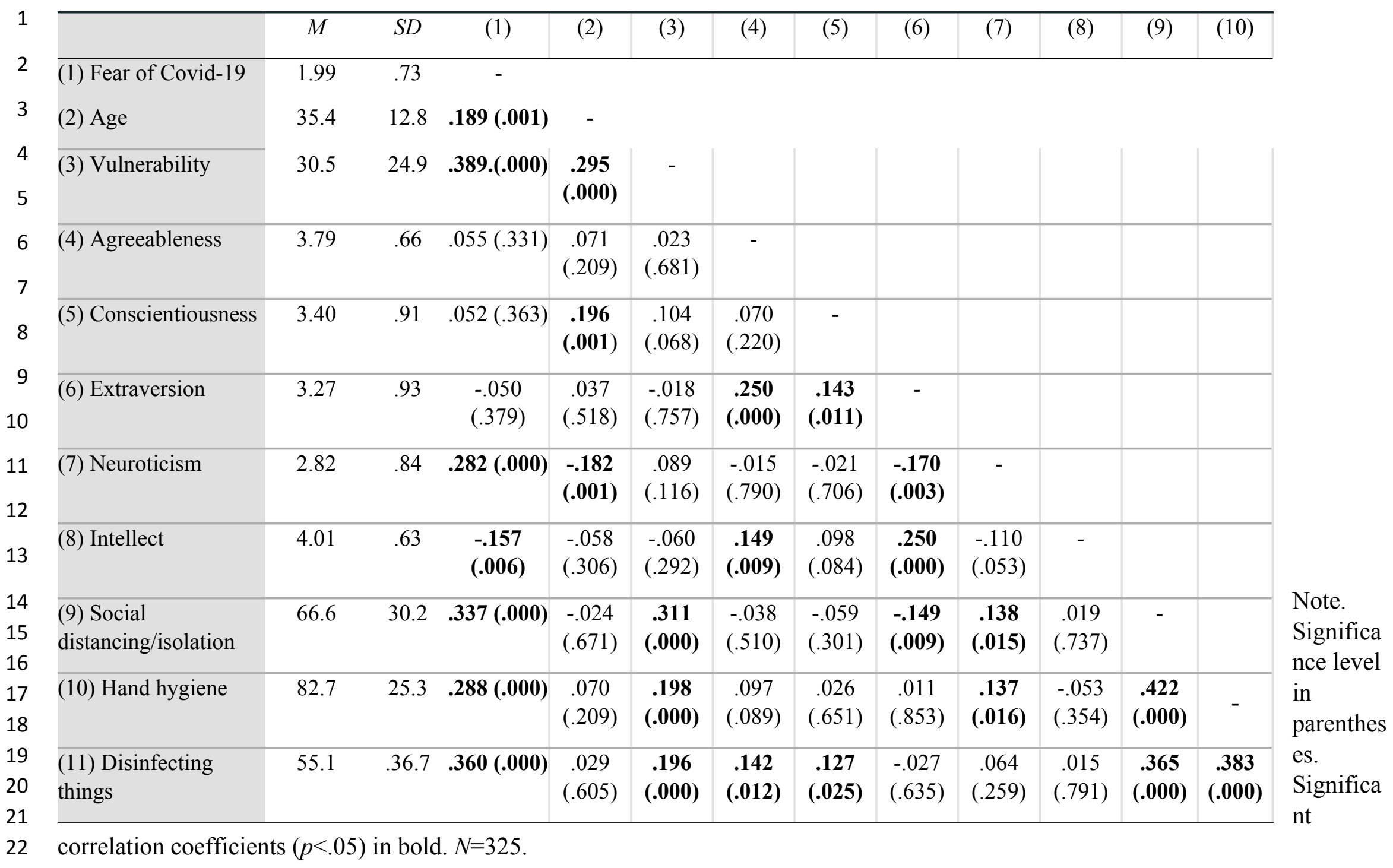

